\title{
LLNL ELECTRICAL SAFETY COMMITTEE SUMMARY REPORT FOR 1993 AND 1994
}

\author{
W. A. NIVEN \\ S. R. TROST \\ LLNL ELECTRICAL SAFETY COMMITTEE
}

March, 1995

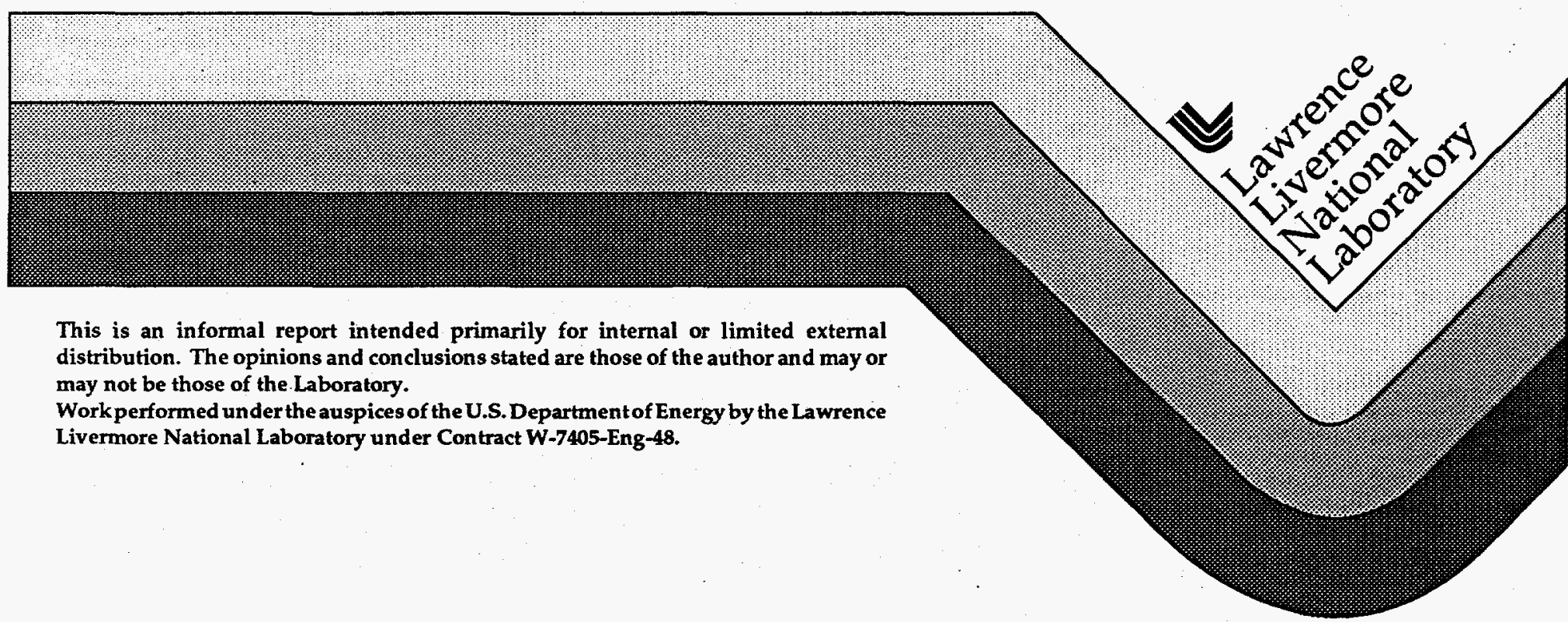




\section{DISCLAIMER}

This document was prepared as an account of work sponsored by an agency of the United States Government. Neither the United States Government nor the University of California nor any of their employees, makes any warranty, express or implied, or assumes any legal liability or responsibility for the accuracy, completeness, or usefulness of any information, apparatus, product, or process disclosed, or represents that its use would not infringe privately owned rights. Reference herein to any specific commercial product, process, or service by trade name, trademark, manufacturer, or otherwise, does not necessarily constitute or imply its endorsement, recommendation, or favoring by the United States Government or the University of California. The views and opinions of authors expressed herein do not necessarily state or reflect those of the United States Government or the University of California, and shall not be used for advertising or product endorsement purposes.

This report has been reproduced directly from the best available copy.

Available to DOE and DOE contractors from the Office of Scientific and Technical Information P.O. Box 62, Oak Ridge, TN 37831

Prices available from (615) 576-8401, FTS 626-8401

Available to the public from the National Technical Information Service

U.S. Department of Commerce 5285 Port Royal Rd., Springfield, VA 22161 


\section{DISCLAIMER}

Portions of this document may be illegible in electronic image products. Images are produced from the best available original document. 


\section{TABLE OF CONTENTS}

Page

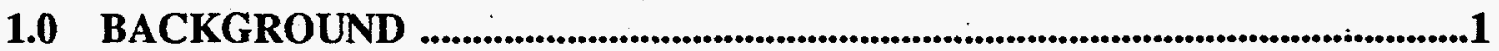

2.0 ORGANIZATION ..........................................................................................1

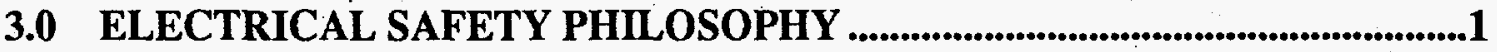

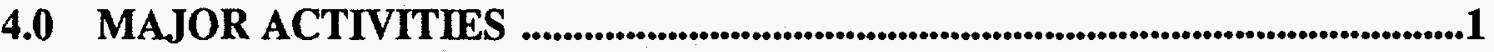

4.1 Review of DOE's Model Electrical Safety Program ..................................1

4.2 LLNL Electrical Safety Performance Measurement .................................2

4.3 Review of LLNL Electric Shock Emergency Response Policy ..................3

4.4 Thank You Letter to Encourage Reporting of Minor Electrical Shocks .. .3

4.5 Electrical Safety Improvements and Corrective Actions .........................3

4.6 Electric Shock Emergency Response Process Action Team ......................4

4.7 Revision of LLNL Health and Safety Chapter 23........................................5

4.8 Evaluation of OSHA Training Requirements ........................................5

4.9 Self-evaluation of LLNL's Electrical Safety Program ..............................5

4.10 Safety Culture Improvement Program ...................................................5

4.11 TQM and Safety Management ...........................................................66

5.0 ELECTRICAL SAFETY COMMITTEE FORMATION MEMORANDUM .............................................................................................

6.0 ELECTRICAL SAFETY COMMITEE CHARTER .................................8

7.0 LLNL ELECTRICAL SAFETY COMMITTEE MEMBERSHIP ..................9

8.0 LLNL ELECTRICAL SAFETY COMMITTEE SUBCOMMITTEES ......... 10

9.0 REVIEW OF SUPERVISOR'S ACCIDENT ANALYSIS REPORTS .......... 11 


\title{
LLNL ELECTRICAL SAFETY COMMITTEE
}

\author{
SUMMARY REPORT
}

FOR

1993 AND 1994

W. A. Niven ${ }^{1}$ and S. R. Trost ${ }^{2}$

\subsection{BACKGROUND}

The Electrical Safety Committee (ESC) was formed on March 3, 1993 by Duane Sewell to advise the ES\&H Council on policies, procedures and programs to improve the Laboratory's electrical safety performance. Duane Sewell's formation memorandum and charter is attached for information. With the reorganization of the Director's office in the fall of 1993, the Senior Management Council reviewed and continued the ESC's advisory function and assigned Dennis Fisher to be the cognizant Associate Director.

\subsection{ORGANIZATION}

The ESC is presently organized with three subcommittees: Guidelines and Regulations, Programs and Training, and Performance Measurement and Analysis. Current membership is attached for information, as well as the charters of the three subcommittees. The committee at large meets once a quarter, the Executive Committee, comprised of the Committee Chair, the Executive Secretary and the Subcommittee Chairs meets twice quarterly, and the subcommittees meet once or twice per month. Minutes of meetings are distributed to the ES\&H Working Group and senior Laboratory management.

\subsection{ELECTRICAL SAFETY PHILOSOPHY}

The ESC agrees that electrical safety is an integral part of a comprehensive industrial safety program. There are many areas where maintaining high standards of electrical safety are very dependent on maintaining high standards of overall industrial safety.

LLNL site management uses a graded approach to safety. Serious safety deficiencies receive resources and attention immediately. Less serious deficiencies are addressed based on priorities consistent with available resources. LLNL management is committed to continuously improve safety; these philosophies are consistent with ESC actions.

\subsection{MAJOR ACTIVITIES}

\subsection{Review of DOE's Model Electrical Safety Program}

The ESC reviewed the Department of Energy (DOE) Model Electrical Safety Program early in 1994. The model program was developed by DOE to serve as guidance for the entire DOE complex for developing and maintaining an effective and sound electrical safety program.

\footnotetext{
${ }^{1}$ Committee Executive Secretary

${ }^{2}$ Committee Chairman
} 
Four ESC members were among 22 LLNL employees who attended the DOE's Model Electrical Safety Program workshop in January 1994. Following the workshop, a summary of the DOE Model Program was also presented to 24 members of Laboratory management. (One ESC member contributed to the development of the DOE Model Electrical Safety Program and was part of the workshop briefing team.) The DOE Model Program was also the subject of discussion at several ESC meetings.

In general, the ESC feels that many of the components of LLNL's safety policies and practices are commensurate with the DOE Model Electrical Safety Program. For the present, no specific policy recommendations have been developed.

DOE's Model Electrical Safety Program guidance recommends the establishment of an Authority Having Jurisdiction (AHJ) for interpreting the electrical requirements of Occupational Safety And Health Administration (OSHA), National Electrical Code (NEC), and other standards and orders applicable to the site or its facilities. The Guidelines and Regulations Subcommittee plans to develop an $\mathrm{AHJ}$ policy recommendation during the course of 1995.

\subsection{LLNL Electrical Safety Performance Measurement}

The Performance Measurement and Analysis Subcommittee has performed evaluations of LLNL Supervisor's Accident Analysis Reports (SAARs) for 1993 and 1994. The latest report is attached for information and summarized below.

A number of common themes recur in the incidents, including:

- unnecessary electrically energized work (failure to employ lock and tag procedures)

- disregard for applicable policies and procedures
- poorly maintained equipment, extension cords, plugs and receptacles

- shocks from improper handling of plugs of all types

- shocks during repair of facility air conditioning units

- shocks during overhead fluorescent light repair

- static shocks from poorly grounded vacuum cleaners

The report summarizes the SAAR electrical shock incidents according to root causes. The most common root cause category is found to be lack of knowledge or appreciation of the hazard. It is observed that a significant fraction (approximately 1/3) of such occurrences appear to be the result of negligence or disregard of policy and procedure by people who should be fully capable of understanding and appreciating the hazards at hand. Equipment condition and maintenance also continues to be a significant contributor to shock incidents, highlighting the need for periodic inspection and maintenance of items such as cords, plugs and receptacles. During the course of 1995, the ESC plans to focus further attention on improving electrical safety in the primary root cause categories.

In addition to root cause categories, the report summarizes the SAAR electrical shock incidents according to "type of work." Two questions were asked: 1) did individuals believe they were engaged in electrical work, and 2) if they believed that they were engaged in electrical work was the work intended to be performed while electrically energized?

In 9 of the 24 total incidents in 1994, the individuals that received shocks did not believe that they were engaged in 
"electrical work. " Examples of this type were shocks associated with office equipment and appliances such as coffee pots and static shocks from computer screens and vacuum cleaners. Of the 15 that did believe they were engaged in "electrical work," 9 did not intend that the work was to be performed in such a manner that they could come in contact . with electrically energized parts.

Examples in this category are insulation failure on poorly maintained equipment such as extension cords that unexpectedly exposed the worker to electrically energized parts; grounding system failures on poorly maintained equipment that unexpectedly exposed the worker to electrically energized parts that are normally at ground potential; and bypass of mechanical insulation barriers such as carelessly touching the male pins while unplugging an electrical plug from its receptacle. Examples of the 6 incidents in which the workers did believe that they could come in contact with electrically energized parts are shocks that occurred during repair of overhead fluorescent lights and facility air conditioning units.

The LLNL Supervisor's Accident Reports are generally a good source of summary information from which real indicators can be extracted. However, the Performance Measurement and Analysis Subcommittee feels that there are several areas that can be improved and strengthened and plans to address these in 1995. Also, the subcommittee plans to examine in greater depth the accident/near-miss severity trends.

\subsection{Review of LLNL Electric Shock Emergency Response Policy}

The ESC strongly supports LLNL's policy of reporting all electrical shock incidents, however minor, and transporting the victim to medical. The policy of reporting all electric shock incidents is designed to provide not only maximum protection for the health of the workers involved, but is also of vital importance in providing the opportunity to improve electrical safety.

\subsection{Thank You Letter to Encourage Reporting of Minor Electrical Shocks}

As a positive incentive to encourage people to report minor electrical shock incidents, the ESC recommends that individuals who report electric shock incidents and are transported to medical should be formally thanked by LLNL management.

Beginning in November, 1994, a thank you letter signed by Stan Trost as ESC Chairman is sent to anyone that reports an electrical shock incident and goes to medical.

\subsection{Electrical Safety Improvements and Corrective Actions}

Information that is learned from analyzing electrical safety incidents is used to make corrections and improvements in work practices, equipment safety, worker education and training, etc. Examples of such electrical safety improvements and corrections are as follows:

- In a number of incidents, it was found that employees did not properly recognize and deal safely with energized electrical work situations. A new Hazards Control Course to teach OSHA energized electrical work requirements in the R\&D electronics context has been developed to respond in part to this problem. Two classes have been given to date with a total of approximately 50 employees attending. To the best of our knowledge this is the first course of its type in the DOE complex, and possibly in the country.

- In several incidents, lockout/tagout training was not adequately translated into safe work practices. Follow-up actions were taken by the 
individuals' supervision.

Lockout/tagout guidance and training is being revised.

- System documentation deficiencies have been a contributing cause of a number of shocks. In part to address this problem, a new Electrical Engineering Standard on Electronics Documentation, Engineering Quality, and Configuration Management has been issued.

- One shock was caused by defective grounding in older Plugmold outlet strips. Safety alerts were issued calling for the defective equipment to be replaced.

\subsection{Electric Shock Emergency Response Process Action Team}

As an Engineering initiative, an Electric Shock Emergency Response Process Action Team (PAT) was established in March 1994. The PAT was established as a direct result of one of the findings in the ADGAP Institute's safety system assessment of the Engineering Directorate in September 1993. ADGAP reported employees' estimates that one half of all minor electric shocks may go unreported as a result of a number of disincentives for reporting the incidents.

If half of the minor electric shocks that occur are not reported, then an important flow of information is missing about workplace hazards and potential causes that could lead to a serious accident. It is therefore of critical importance to safety improvement that barriers to reporting minor shocks and near misses be eliminated or reduced and incentives be increased. The PAT's objective is to recommend a new improved policy for on-scene evaluation of electric shock incidents, improved emergency response processes, and improved processes for gathering of information for incident analysis and follow up actions.

So far, the PAT has defined the present emergency response process and tentatively mapped out a safety system improvement process. The PAT has also identified and prioritized a number of incident reporting disincentives which include fear, miscommunication, program attitude, historical work environment, and visibility of the emergency response. These are described further below:

- Fear includes such factors as having done a job wrong or the wrong job, the numerous interviews that the individual is subjected to, personal embarrassment, over response, potential impact on performance appraisal, potential impact on salary, and peer pressure.

- Miscommunication includes factors such as self-evaluation of severity of a shock and its consequences, denial, lack of knowledge or incorrect beliefs about how information from the root-cause process will be used, and poor training in Laboratory policy.

- Program attitude includes factors such as taking shortcuts to meet perceived program objectives and lack of clear LLNL policy communication and follow-through on reporting of shocks.

- Historical work environment includes factors such as culture support system (includes "macho" attitude), and a false sense of security stemming from having been shocked several times before without adverse consequences and believing that being shocked is a normal consequence of the job.

- Visibility of the emergency response is associated with the embarrassment that individuals have with being transported to medical in the ambulance when in fact there may be no serious injury.

The PAT expects to complete its current work by June 1995. The PAT will 
address those disincentives that are within its charter, such as embarrassment and fear of the medical system, but many of the most important disincentives involve organizational and cultural issues that are beyond the PAT's purview. Examples of the latter include fear of retaliation in salary or ranking (whether well-founded or not), policy communication, and others.

\subsection{Revision of LLNL Health and Safety Chapter 23}

The Guidelines and Regulations Subcommittee has actively participated in the extensive revision and editing of LLNL's Health and Safety Chapter 23 to incorporate OSHA requirements. The ESC completed its review at the end of 1994. The draft is currently being finalized by TID and will be submitted to the ES\&H Working Group and Laboratory management for final review, approval, and release.

\subsection{Evaluation of OSHA Training Requirements}

The Electrical Safety Programs and Training Subcommittee is evaluating OSHA electrical safety training requirements for the Laboratory's various electrical hazard exposure groups. A focus group of Electrical Engineering, Mechanical Engineering, and Plant Engineering technician supervisors, and the Electrical Engineering and Hazards Control Safety Engineers was created by the subcommittee. The focus group developed a matrix of OSHA training requirements correlated with the Laboratory's various electrical hazard exposure groups, and expects to issue its findings early in 1995. Review of the adequacy of LLNL's training classes by the subcommittee will follow later in 1995.

\subsection{Self-evaluation of LLNL's Electrical Safety Program}

In March 1993 the ESC participated in drafting LLNL's Electrical Safety SelfEvaluation which was submitted to DOE. This was the first attempt to comprehensively evaluate the strengths of LLNL's electrical safety elements and practices and to identify areas needing improvement.

\subsection{Safety Culture Improvement Program}

The ESC endorses and encourages organizations across the Laboratory to develop a positive industrial and electrical safety improvement environment. The ESC notes Plant Engineering's substantial effort toward this end.

Beginning approximately four years ago, working with safety consultants, Plant Engineering established a safety culture improvement program that is beginning to achieve success. Their Safety Council is employee run. It has wide latitude to develop safety policy with management, affect work practices, influence worker safety attitudes and promote worker safety involvement. Safety communication throughout Plant Engineering has improved, employee involvement has increased, their safety suggestion program is strong, their reporting of minor accidents has increased significantly, and most importantly, their reportable accident rates have decreased by approximately $25 \%$ between December 1993 and December 1994 and are substantially lower than those for comparable work in industry. 


\subsection{TQM and Safety Management}

LLNL Engineering sponsored a working conference in November 1993 to explore state-of-the-art Total Quality Management (TQM) concepts and methodologies as a means for managing and improving safety. The conference was well attended by safety managers from a number of industrial companies and government laboratories including Dupont, General Electric, Stanford Linear Accelerator, Sandia Corporation and LLNL. The conference was viewed as highly successful by the participants as all are looking for ways to improve safety performance and TQM concepts are at the center of many of their new safety management strategies. All agreed that more research is needed to find more and better ways to improve safety performance in their respective organizations. Because of the interest that has been generated, a follow-on working conference is planned this spring in Albuquerque. 


\title{
MEMORANDUM
}

TO: . Distribution

FROM

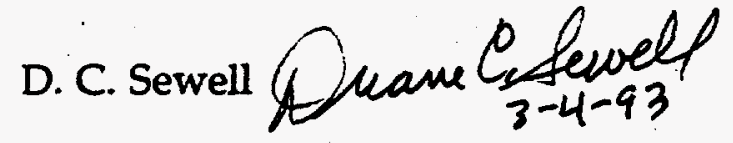

\section{SUBJECT: ELECTRICAL SAFETY COMMITTEE MEMBERSHIP}

An Electrical Safety Committee (ESC) has been formed to advise the ES\&H Council on policies, procedures and programs to improve the Laboratory's electrical safety performance. Stan Trost, Committee Chair, submitted a proposed list of Committee members which I approved:

\author{
Henry Bell \\ Charles Cain \\ Curtis Clower \\ Donald B. Davis \\ Dick Emmert \\ Robert Hornaday \\ Jim Jackson \\ Dick O’Neil \\ Orville Paul \\ Paul Weber \\ Bill Nevin, Executive Secretary
}

I want to thank each of you for your willingness to assist the Laboratory concerning electrical safety. The Electrical Safety Committee will have an important role in assuring the safe conduct of operations at LLNL.

DCS:sl

Distribution:

Electrical Safety Committee Members
Information:

D. R. Beach

G. W. Campbell

J.W. Cook

R. A. Corallo

G. E. Cummings

A. J. Toy

S. R. Trost 


\section{CHARTER \\ ELECTRICAL SAFETY COMMITTEE}

\section{PURPOSE}

The Electrical Safety Committee advises the ES\&H Council on policies, procedures. and programs to improve LLNL's electrical safety performance.

\section{MEMBERSHIP}

The Deputy Director will appoint a chaiperson. The chairperson will appoint committee members, subject to approval by the Deputy Director. Members are selected from Laboratory management, professional and technical staff and are expected to have technical competence in electrical systems and represent LLNL organizations.

\section{FUNCTIONS}

The Electrical Safety Committee serves in an advisory capacity to the ES\&H Council. The Electrical Safety Commitie:

- Develops and updates criteria to be used for electrical safety performance measurement and recommends these for approval by the ES\&H Council.

- Sponsors appropriate employee-management subcommittees or working groups and serves as a conduit to ensure that employee concerns and suggestions on electrical safety improvement are brought before the ES\&H Council.

- Sponsors analytical activities requested by the ES\&H Council or originated by the Electrical Safety Committee.

- Reviews Incident Analyses, occurrence reports and near misses relating to electrical safety, identifies lessons learned and common themes, i.e., root cause, and distributes this information to Laboratory management.

- Conducts annual reviews of the Health and Safery Manual, Chapter 23.

- Reviews existing electrical safety programs: recommends new programs as appropriate.

- Reviews electrical safety training and provides recommendations to the Training Program Oversight Committee concerning suggested improvements.

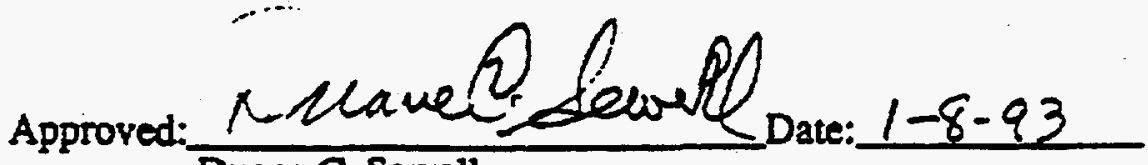

Duane C. Sewell

ES\&H Council Chaiman 


\section{LLNL ELECTRICAL SAFETY COMMITTEE}

\section{MEMBERSHIP}

1/15/95

Members

Henry Bell

Charles Cain

Curtis Clower

Donald B. Davis

Don T. Davis

Ros Marrs

Jim Jackson

Bill Niven

Orville Paul

Stan Trost

Paul Weber

Associates:

Don Campbell

Martin Loomis

Larry Moon

William Silver

Ed Vittorio

Jim Wells

John Wilson
Organization

Energy Programs

Plant Engineering/Maintenance and Operations

Laser Programs/ICF

Computations

Engineering Research Division

Physics

Hazards Control

Laser Engineering Division

Plant Operations/Assurance Office

Electronics Engineering

Laser Programs/ISAM

Safety Engineer, Laser Engineering Division Cochair, Engineering Technical Safety Steering Committee

Staff Engineer, Assurance Review Office

Safety Engineer, Hazards Control

Safety Engineer, Hazards Control

Plant Engineering, Maintenance and Operations

Safety Engineer, Engineering 


\section{LLNL ELECTRICAL SAFETY COMMITTEE SUBCOMMITTEES}

1/15/95

Electrical Safety Guidelines and Regulations. Serves as an advisory group on electrical safety guidelines and regulations. Performs annual review of Chapter 23 of the H\&S Manual. Resolves conflict among differing codes and regulations.

Members:

Curtis Clower Chair

Orville Paul Alt Chair

Associates:

Don T. Davis

Don Campbell

Ed Vittorio

Jim Jackson

John Wilson

Electrical Safety Programs and Training. Reviews existing electrical safety programs and recommends improvements. Reviews electrical safety training for completeness and effectiveness. Helps promote safety awareness and knowledge. Obtains speakers.

Submits/coordinates safety notes to Newsline and other communications channels.

Members:

Charles Cain Chair

Don B. Davis

Bill Niven
Associates:

Ed Vittorio

Jim Wells

Electrical Safety Performance Measurement and Analysis. Helps develop meaningful, quantitative safety performance measures and statistics. Reviews incident report, occurrence report, and near miss analyses. Evaluates validity of data, trends, and conclusions. Evaluates root cause analyses. Extracts information and helps develop lessons learned. Promotes feedback of electrical safety information to improve electrical safety performance of LLNL employees.

Members:

Paul Weber

Chair

Associates

Henry Bell

Larry Moon

Don T. Davis

William Silver

Orville Paul

Ed Vittorio 
Interdepartmental letterhead

Mail Station L-463

Ext 3-2076

January 17, 1995

CL 95-01 File \#A711

TO: Distribution

FROM: $\quad$ P. D. Weber

SUBJECT: $\quad$ Review of Supervisor's Accident Analysis Reports

Following are the results of an evaluation conducted by the LLNL Electrical Safety Committee, Subcommittee on Performance Measures, of electrical safety incidents for the second half of calendar year 1994. This is the third such analysis performed. Data from the previous analysis covering calendar year 1993, and for the first half of 1994, is also presented for comparison. We have attempted to group incidents by general cause and type of work involved. For the first time we have also included information from "near misses", even if these did not result in Supervisors Accident Analysis Reports (the primary source of information for shock incidents).

Causes (some accidents had more than one root cause)

$\underline{1993}$

$1 / 94-6 / 94 *$

7/94-12/94

Number of incidents evaluated

Lack of knowledge or appreciation of hazard

Equipment condition/maintenance

Equipment appropriateness

Design, fab, or installation error

Communication (wrong information)

Could not determine

*revised due to late data

University of California
15

$50 \%$

6

7

$78 \%$

3

$33 \%$

9

$30 \%$

1

$11 \%$

7

$23 \%$

1

$3 \%$

1

$3 \%$
1

$11 \%$

0

$12 \%$
$7 \%$

10

$66 \%$

5

$33 \%$

1

2

$13 \%$

0

1 $7 \%$ 
Did worker believe he was engaged in "electrical work"?

$\begin{array}{llll}\text { yes } & 18 & 7 & 8 \\ & 60 \% & 88 \% & 53 \% \\ \text { no } & 12 & 2 & 7 \\ & 40 \% & 22 \% & 47 \%\end{array}$

If electrical work, was it intended to be "hot work"?

$\begin{array}{llll}\text { yes } & 6 & 3 & 3 \\ & 33 \% & 43 \% & 38 \% \\ \text { no } & 12 & 4 & 5 \\ & 67 \% & 57 \% & 62 \%\end{array}$

\section{Type of Electrical Work}

Facility/utility

Research

Other

$\begin{array}{lll}8 & 2 & 2 \\ 44 \% & 29 \% & 25 \%\end{array}$

$\begin{array}{lll}9 & 5 & 6 \\ 50 \% & 71 \% & 75 \%\end{array}$

1

$6 \%$
$0 \quad 0$

A number of common themes recur in these incidents, including:

- static shocks from poorly grounded vacuum cleaners

- poorly maintained cords and plugs

- shocks from handling plugs of all types

- shocks during repair of air conditioning units

- unnecessary hot work (failure to employ lock and tag)

- shocks during fluorescent light repair

- disregard for policy and procedure (even when warned)

The primary root cause category continues to be lack of knowledge or appreciation of the hazard. We have observed, however, that a significant fraction (approximately $1 / 3$ ) of such occurrences appear to be the result of negligence or disregard, by people who should be fully capable of understanding and appreciating the hazards at hand.

These trends will continue to be examined and reported periodically.

PDW:lg

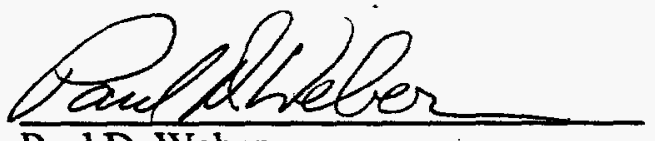

